\title{
A new laboratorial method for the diagnosis of gastrointestinal parasites in dogs
}

Um novo método laboratorial para diagnóstico de parasitos gastrointestinais em cães

Willian Marinho Dourado Coelho ${ }^{1 *}$; Jancarlo Ferreira Gomes²; Alessandro Francisco Talamini do Amarante ${ }^{3}$; Katia Denise Saraiva Bresciani' ${ }^{1}$; Giuliano Lumina ${ }^{3}$; Sumie Koshino-Shimizu4;

Denise Pereira Leme'; Alexandre Xavier Falcão

\author{
${ }^{1}$ Universidade Estadual Paulista - UNESP, CEP 16050-680, Araçatuba, SP, Brasil \\ ${ }^{2}$ Instituto de Biologia e Instituto de Computação, Universidade Estadual de Campinas - UNICAMP, , \\ Distrito de Barão Geraldo, Campinas, SP, Brasil \\ ${ }^{3}$ Instituto de Biociências, Universidade Estadual Paulista - UNESP, Botucatu, SP, Brasil \\ ${ }^{4}$ Instituto de Medicina Tropical, Universidade de São Paulo - USP, São Paulo, SP, Brasil \\ ${ }^{5}$ Faculdade de Medicina Veterinária, Fundação Municipal de Ensino Superior de Bragança Paulista, \\ Bragança Paulista, SP, Brasil
}

Received January 14, 2012

Accepted April 10, 2012

\begin{abstract}
In this study, we aimed to introduce a new technique called TF-Test Modified/Dog for the diagnosis of gastrointestinal parasites in dogs. Fecal samples from 106 dogs were processed by the technique TF-Test Modified/Dog and the techniques of centrifugation-flotation in zinc sulfate, simple-flotation by saturated solution of sodium chloride, direct microscopy exam and TF-Test Conventional. Sensitivity was higher in the TF-Test Modified/Dog (98.41\%), followed by flotation in saturated zinc sulfate $(77.78 \%)$, TF-Test Conventional $(73.02 \%)$, flotation by saturated sodium chloride $(55.55 \%)$, and direct microscopy exam (30.16\%). The diagnostic efficiency varied from $58.49 \%$ to $99.06 \%$, with the highest value also obtained by the new proposed technique. Efficiency level of 99.06\% with kappa index 0.979 (almost perfect) was obtained with the TF-Test Modified/Dog. These results represent significant statistical gains $(\mathrm{P}<0.05)$ of $20.63 \%$ in sensitivity and $12.27 \%$ in efficiency over the best among the other techniques - flotation by saturated zinc sulfate, whose kappa index was 0.738, much lower than that of the TF-Test Modified/Dog. All techniques presented 100\% specificity. In this sense, the high sensitivity of the TF-Test Modified/Dog makes it suitable for epidemiological surveys of gastrointestinal parasitosis in dogs, zoonoses control and preventive surveillance programs.
\end{abstract}

Keywords: Canine gastrointestinal parasites, TF-Test Modified/Dog, faeces analysis, parasitological techniques.

\section{Resumo}

O objetivo deste estudo foi introduzir a nova técnica TF-Test Modified/Dog para diagnóstico de parasitos gastrointestinais em cães. Amostras fecais de 106 cáes foram processadas pela técnica de TF-Test Modified/Dog e também por técnicas de centrifugação-flutuação em sulfato de zinco, flutuação simples em solução saturada de cloreto de sódio, exame microscópico direto e TF-Test Convencional. A sensibilidade foi maior no TF-Test Modified/Dog (98,41\%), seguido por centrífugo-flutuação em solução de sulfato de zinco (77,78\%), TF-Test Convencional (73,02\%), flutuação em solução saturada de cloreto de sódio $(55,55 \%)$, e exame microscópico direto $(30,16 \%)$. A eficiência diagnóstica variou de $58,49 \%$ a 99,06\%, com maior valor obtido pela nova técnica. Foi obtido com o TF-Test Modified/Dog eficiência de 99,06\%, com índice kappa de 0,979 (Quase perfeito). Estes resultados representam ganhos estatisticamente significativos $(\mathrm{P}<0,05)$ de $20,63 \%$ de sensibilidade e $12,27 \%$ de eficiência sobre a melhor entre as outras técnicas empregadas, centrífugo-flutuação em solução de sulfato de zinco, cujo índice kappa foi 0,738 , bem menor do que o TF-Test Modified/Dog. Todas as técnicas apresentaram especificidade de $100 \%$. Nesse sentido, a sua alta sensibilidade o torna adequado para levantamentos epidemiológicos das parasitoses gastrointestinais em cáes, bem como para programas de controle de zoonoses e de vigilância preventiva.

Palavras-chave: Parasitos gastrintestinais caninos, TF-Test Modified/Dog, exame de fezes, técnicas parasitológicas.

\footnotetext{
${ }^{*}$ Corresponding author: Willian Marinho Dourado Coelho

Universidade Estadual Paulista - UNESP, Rua Clóvis Pestana, 793,

CEP 16050-680, Araçatuba, SP, Brasil

e-mail: willianmarinho@hotmail.com
} 


\section{Introduction}

The scientific literature reports divergence between the efficiency of different methods for the diagnosis of gastrointestinal parasites in dogs (FOREYT, 1989; TÁPARO et al., 2006; KATAGIRI; OLIVEIRA-SEQUEIRA, 2008). Dogs can as act as sources of infection of gastrointestinal parasites for humans (XIAO et al., 2007; RODIE et al., 2008; BRIDGER; WHITNEY, 2009). In order to evaluate the true extent of the emerging zoonoses, sensitive diagnostic techniques should be widely available (McCARTHY; MOORE, 2000; MEIRELES, 2010). Besides that, improved methods for the detection of parasites in animals and environment would allow for more effective control measures and monitoring strategies.

Among the techniques proposed for fecal examinations in animals, the most common methods for detection of canine gastrointestinal parasitosis are centrifugation-flotation (OLIVEIRASEQUEIRA et al., 2002), simple-flotation (SOUSA et al., 2010) and microscopy exam (HENDRIX; ROBINSON, 2006). The technique called Three Fecal Test (TF-Test), here and forth referred to as TF-Test Conventional, was proposed for the diagnosis of intestinal parasites in humans, showing high diagnostic sensitivity (HOSHINO-SHIMIZU et al., 2001; GOMES et al., 2004). The first study using TF-Test Conventional for gastrointestinal parasite detection in animals, specifically in sheep (Ovis aries), was reported by Lumina et al. (2006). The results showed that the TF-Test Conventional could be more sensitive than the modified Gordon \& Whitlock technique (UENO; GONÇALVES, 1998) and the techniques of flotation by sodium chloride and direct microscopy exam (GOMES et al., 2006).

In this work, we revisited the methods for dogs by proposing a considerable improvement in the TF-Test Conventional technique with the establishment of TF-Test Modified/Dog, comparing it with the techniques of centrifugation-flotation by saturated solution of zinc sulfate, simple-flotation by saturated solution of sodium chloride and direct microscopy exam. The sensitivity, specificity and efficiency of each technique and their agreement with the Kappa (k) index were determined, classifying them as Poor, Low, Moderate, Substantial and Almost perfect.

\section{Materials and Methods}

\section{Sample collections and laboratory tests}

Fecal samples were obtained from 106 dogs kept in kennels in the cities of Botucatu and Bragança Paulista, State of São Paulo, Brazil. A single stool sample was collected from each dog to perform the techniques of centrifugation-flotation by saturated solution of zinc sulfate (FAUST et al., 1938), simple-flotation by saturated solution of sodium chloride (WILLIS, 1921) and direct microscopy exam (KATO; MIURA, 1954). For the TF-Test Conventional (GOMES et al., 2004) and TF-Test Modified/Dog (FALCÁO et al., 2010), fecal samples from each animal were collected using the TF-Test kit in three alternate days.

\section{Statistical analysis}

The diagnostic sensitivity, specificity and efficiency of each technique were determined by comparison with reference data. The union of the positive results found by each of the five techniques studied was used as a reasonable approximation of the true positivity (FLEISS, 1981; MacLURE; WILLET, 1987). Similarly, the intersection of the true negative results in all five techniques was also used as reference. The agreement of the techniques with these reference data was calculated by the Kappa ( $k$ ) index, statistically testing the consistency of $k$ and ranking it as: Poor (0 to 2.0); Low (0.21 to 0.40$)$; Moderate (0.41 to 0.60 ); Substantial (0.61 to 0.80$)$; and Almost perfect (0.8 to 1.0), according to Gomes et al. (2004).

\section{Results}

According to the statistical criteria above, 63 (59.42\%) dogs showed positive results by at least one technique, whereas the remaining 43 (40.57\%) dogs were considered negative by all five techniques. Among the infected animals, it was possible to verify that $51(82.26 \%)$ dogs had a single type of parasite infection, $8(12.90 \%)$ revealed double infections, and $3(4.84 \%)$ presented triple infections. In the individual evaluation, the positivity was higher in the TF-Test Modified/Dog (58.49\%), followed by flotation by saturated zinc sulfate (47.17\%), TF-Test Conventional (43,39\%), flotation by saturated sodium chloride (33.02\%), and direct microscopy exam (17.92\%), as shown in Table 1. Single infections were predominantly detected by each of the five techniques, but they varied from $29.03 \%$ to $82.26 \%$.

Sixty-three dogs were infected by seven parasite species (Table 2). Infections by three protozoa species were found in 31 (49.21\%) dogs and infections by four species of helminths were found in 32 (50.79\%) dogs. Among the gastrointestinal parasite species, Giardia spp. and Ancylostoma spp. were detected in a large number of dogs, followed by Entamoeba spp., Trichuris vulpis, Toxocara canis, Isospora spp., and Spirocerca lupi.

The diagnostic performances of the five techniques are shown in Table 3, with the TF-Test Modified/Dog technique presenting the highest sensitivity and efficiency among them. All techniques were able to detect the same 43 dogs as negative, so they presented $100 \%$ specificity.

The kappa indexes $(k)$ of the five techniques are shown in Table 4, with statistically significant values $(\mathrm{P}<0.05)$. The TF-Test Modified/Dog was ranked as Almost perfect, whereas the other techniques were ranked from Substantial to Moderate.

\section{Discussion}

The positive diagnosis of canine gastrointestinal parasitosis depends on the parasitological technique adopted (GOMES et al., 2006; TÁPARO et al., 2006; KATAGIRI; OLIVEIRA-SEQUEIRA, 2010). In this context, the present study demonstrates interesting aspects of the techniques studied, with significant differences in sensitivity and efficiency. 
Table 1. Positivity and type of infection found in the study of 106 dogs by five parasitologic techniques for fecal examination.

\begin{tabular}{|c|c|c|c|c|c|}
\hline \multirow{2}{*}{ Technique } & \multirow{2}{*}{ Positivity (\%) } & \multicolumn{3}{|c|}{ Type of Infection } & \multirow{2}{*}{$\begin{array}{c}\text { Total infection } \\
\text { number }\end{array}$} \\
\hline & & simple & double & triple & \\
\hline TF-Test Modified/Dog & $62(58.49)$ & 51 & 8 & 3 & 76 \\
\hline Flotation by Saturated Zinc Sulfate & $50(47.17)$ & 43 & 6 & 1 & 58 \\
\hline TF-Test Conventional & $46(43.39)$ & 36 & 8 & 2 & 58 \\
\hline Flotation by Saturated Sodium Chloride & $35(33.02)$ & 32 & 2 & 1 & 39 \\
\hline Direct microscopy exam & $19(17.92)$ & 18 & 1 & 0 & 20 \\
\hline
\end{tabular}

$\%$ - percentage.

Table 2. Parasite species detected in the study of 106 dogs by five parasitologic techniques.

\begin{tabular}{|c|c|c|c|c|c|c|}
\hline Parasite specie & TF-Test M (\%) & FSZS (\%) & TF-Test C (\%) & FSSC (\%) & Direct exam (\%) & Total (\%) \\
\hline Isospora spp. & $1.89(2)$ & $1.89(2)$ & - & $1.89(2)$ & - & $1.89(2)$ \\
\hline Entamoeba spp. & $12.26(13)$ & $8.49(9)$ & $5.66(6)$ & $1.89(2)$ & - & $12.26(13)$ \\
\hline Giardia spp. & $15.09(16)$ & $8.49(9)$ & $11.32(12)$ & - & $2.83(3)$ & $15.09(16)$ \\
\hline Toxocara canis & $5.66(6)$ & $4.72(5)$ & $5.66(6)$ & $5.66(6)$ & $3.77(4)$ & $5.66(6)$ \\
\hline Trichuris vulpis & $8.49(9)$ & $7.55(8)$ & $5.66(6)$ & $8.49(9)$ & $3.77(4)$ & $8.49(9)$ \\
\hline Ancylostoma spp. & $15.09(16)$ & $15.09(16)$ & $15.09(16)$ & $15.09(16)$ & $7.55(8)$ & $15.09(16)$ \\
\hline Spirocerca lupi & - & $0.94(1)$ & - & - & - & $0.94(1)$ \\
\hline Total & $58.48(62)$ & $47.17(50)$ & $43.39(46)$ & $33.02(35)$ & $17.92(19)$ & $59.42(63)$ \\
\hline
\end{tabular}

TF-Test $M=$ TF-Test Modified/Dog; FSZS = Flotation by Saturated Zinc Sulfate; TF-Test C = TF-Test Conventional; FSSC = Flotation by Saturated Sodium Chloride; $\%$ - percentage.

Table 3. Diagnostic performance of the five parasitologic techniques in the study of 106 dogs.

\begin{tabular}{lcc}
\hline \multicolumn{1}{c}{ Technique } & Sensitivity (\%) & Efficiency (\%) \\
\hline TF-Test Modified/Dog & $98.41(62 / 63)$ & $99.06(105 / 106)$ \\
FSZS & $79.36(50 / 63)$ & $86.79(92 / 106)$ \\
TF-Test Conventional & $73.02(46 / 63)$ & $83.96(89 / 106)$ \\
FSSC & $55.55(35 / 63)$ & $73.58(78 / 106)$ \\
Direct exam & $30.16(19 / 63)$ & $58.49(62 / 106)$ \\
\hline
\end{tabular}

FSZS = Flotation by Saturated Zinc Sulfate; FSSC = Flotation by Saturated Sodium Chloride; $\%$ = percentage

Table 4. Kappa $(k)$ agreement index for different parasitological techniques found in relation to the reference data.

\begin{tabular}{lcc}
\hline \multicolumn{1}{c}{ Technique } & $\boldsymbol{k}^{*}$ & Rank \\
\hline TF-Test Modified/Dog & 0.979 & Almost perfect \\
FSZS & 0.738 & Substantial \\
TF-Test Conventional & 0.686 & Substantial \\
FSSC & 0.502 & Moderate \\
Direct exam & 0.439 & Moderate \\
\hline
\end{tabular}

FSZS = Flotation by Saturated Zinc Sulfate; FSSC = Flotation by Saturated Sodium Chloride; ${ }^{*} \mathrm{P}(<0.05) ; \%$ - percentage.

The proposed technique, TF-Test Modified/Dog, detected 13 infected dogs more than the flotation by the saturated zinc sulfate technique (a gain of 11.32\%), 16 infected dogs more than the TF-Test Conventional (a gain of $15.10 \%$ ), and more than 27 infected dogs with respect to the other techniques (a gain greater than $25.47 \%$ ). These considerable gains in sensitivity can be justified by the combination of various parasitic enrichment processes, such as: a) collection of fecal material in three alternate days using a preservative solution; b) double filtering of the collected fecal samples; c) two stages of parasitic concentration, centrifugation-sedimentation followed by concentration-flotation; and d) reading of two fecal smears, as recommended in the scientific literature (GARCIA, 2007). The collection of fecal samples in three alternate days using preservative solution considerably favors increased detection of parasitic species, including helminths and protozoa (Table 2).
This happens due to the different biological cycles of each parasite species, some of them with intermittent elimination of parasitic structures. In this case, the suppression of parasitic structures elimination can occur for hours, days, weeks or even months (HOSHINO-SHIMIZU et al., 2001; GOMES et al., 2004; GARCIA, 2007). At the same time, the use of preservative solution preserves the morphology of parasites for a period of thirty days at room temperature (GARCIA, 2007). This is essential for a conclusive diagnosis (GOMES et al., 2004). The double-layered sieves eliminate part of the fecal impurities and the two-stage parasitic concentration - centrifugation-sedimentation followed by concentration-flotation, considerably reduces the remaining impurities. The technique of centrifugation-sedimentation concentrates parasitic structures with density higher than $1.19 \mathrm{~g} / \mathrm{mL}$, such as the capsule with eggs of the parasite Dipylidium caninum, for instance. 
The subsequent flotation-concentration aims at the detection of parasitic structures with density lower than $1.19 \mathrm{~g} / \mathrm{mL}$, such as Entamoeba spp., Giardia spp., and Isospora spp. Finally, the TF-Test Modified/Dog adopts two microscope readings. The first aliquot $(60 \mu \mathrm{L})$ examined consists of fecal material processed in the centrifugation-sedimentation step; in the flotation-concentration step, all the sediment from the previous step is used and examined. Helminths and protozoa can be diagnosed in the centrifugationsedimentation aliquot, but after the performance of the flotationconcentration step, protozoa are found in much greater amounts. This way, one can have a good idea of the parasitic infection intensity in dogs.

In the current study, enteroparasitic positivity in dogs varied from $17.92 \%$ to $58.49 \%$, depending on the parasitologic technique. These findings emphasize that the choice of a sensitive technique is fundamental to avoid misdiagnosis and, from the viewpoint of public health, implement effective control programs of zoonoses.

We detected $59.42 \%$ of infected animals and this positivity is consistent to the one reported by Oliveira-Sequeira et al. (2002) for stray dogs in the State of Sao Paulo Brazil, as determined by the association of three different techniques, such as: sedimentation, simple-flotation and centrifugation-flotation. However, in Chubut, Argentina, the association of these three techniques showed lower prevalence of parasitic infections in stray dogs (SÁNCHEZTHEVENET et al., 2003).

The techniques studied also detected $82.26 \%$ of positive dogs with a single type of infection, $12.90 \%$ with double infections, and $4.84 \%$ with triple infections. In other localities, such as Neuquén, Argentina, the reported prevalence of multiple parasitic infections was also lower than the single parasitic infection (SORIANO et al., 2009), by the use of two conventional techniques (flotation and sedimentation). Possibly, stray dogs infected by two or more parasite species have lower natural resistance or immunity than those with only one parasite species or without any infection.

Seven parasite species were identified by the five techniques studied: Ancylostoma spp. was detected in 16 (15.09\%) dogs by four techniques, except the direct microscopy exam, which detected only half of the cases (7.54\%). It is important to emphasize that the adult form of this intestinal helminth, when present in the host, seems to eliminate a great number of eggs, diagnosed even by low sensitive techniques. Other investigators (OLIVEIRASEQUEIRA et al., 2002) have also found, in the State of Sao Paulo, no significant difference in the detection of this helminth infection in dogs by the association of three techniques. Nevertheless, in the diagnosis of Giardia spp. and Entamoeba spp., the TF-Test Modified/ Dog was more sensitive than all the other techniques (Table 2), pointing out the influence of the parasitic enrichment procedures and the collection of fecal samples in three alternate days.

Giardia spp. and Ancylostoma spp. were the most prevalent parasites in this study. These parasite species were also detected with moderate and high prevalence in different localities of the State of São Paulo by different authors (GENNARI et al., 2001; OLIVEIRA-SEQUEIRA et al., 2002). Moreover, five out of seven parasite species, Toxocara canis, Ancylostoma spp., Isospora spp., Giardia spp. and Trichuris vulpis, were also detected by the same authors, along with other investigators from Spain (MARTÍNEZCARRASCO et al., 2007).
The results obtained with the TF-Test Conventional confirm our previous study in dogs (GOMES et al., 2006), showing that the sensitivity of this technique is lower than the one obtained with flotation by saturated zinc sulfate, which differs from its high sensitivity found for sheep and humans (LUMINA et al., 2006; GOMES et al., 2004). Our findings indicate that dogs eliminate parasitic structures of lower specific densities (less than $1.19 \mathrm{~g} / \mathrm{mL}$ most of the times) in comparison to sheep and human parasites, resulting in a higher detection of these structures in the flotation using the saturated zinc sulfate technique. However, some species present specific densities higher than $1.19 \mathrm{~g} / \mathrm{mL}$, such as Dipylidium caninum egg packets, which do not fluctuate, being detected only by centrifugation-sedimentation. That explains the indication of dual processing in the laboratory routine, such as centrifugation-sedimentation and concentration-flotation.

The highest sensitivity was obtained by the TF-Test Modified/ $\operatorname{Dog}(98.41 \%)$, while the sensitivity of the other techniques varied from $30.16 \%$ to $77.78 \%$. This result represents considerable sensitivity gains of $25.39 \%$ and $20.63 \%$ with respect to the other two most sensitive techniques, TF-Test Conventional and flotation by saturated zinc sulfate, respectively. The diagnostic efficiency varied from $58.49 \%$ to $99.06 \%$, with the highest value also obtained by the TF-Test Modified/Dog. All studied techniques presented maximum specificity, since no parasite was found in the same 43 negative dogs.

The agreement of each technique with the reference data revealed similarities and differences between them. The TF-Test Modified/Dog presented a $k$ index ranked as Almost Perfect, being significantly higher than the $k$ indexes of the flotation by saturated zinc sulfate and TF-Test Conventional techniques, both ranked as Substantial. These two techniques, in turn, showed $k$ indexes significantly higher than the flotation by saturated sodium chloride and direct microscopy exam techniques, both at Moderate rank. The TF-Test Modified/Dog has proved to be simple and fast, since it requires less manual handling and less space to be performed. The use of preservative solution prevents the degradation of the parasitic structure, allowing for better visualization.

\section{Conclusions}

The TF-Test Modified/Dog presented the best diagnostic performance in all aspects together with some advantages over the conventional techniques. In this sense, the high sensitivity of the TF-Test Modified/Dog makes it suitable for epidemiological surveys of gastrointestinal parasitosis in dogs, zoonoses control and preventive surveillance programs.

\section{Acknowledgements}

The authors are grateful to the College of Parasitology, Institute of Biosciences, State University of São Paulo - UNESP, Botucatu, for providing the laboratory facilities. We would also like to thank 'ImmunoAssay Ind. Com. S/A.', for the help of one of its technicians and laboratory supplies. We are also grateful to the 'Research Support Foundation of the State of São Paulo' - FAPESP (grants $n^{\circ} 2008 / 57428-4$ and no 2008/50090-8) for the financial support. 


\section{References}

Bridger KE, Whitney H. Gastrointestinal parasites in dogs from the Island of St. Pierre off the south coast of Newfoundland. Vet Parasitol 2009; 162(1): 167-170. http://dx.doi.org/10.1016/j. vetpar.2009.02.016

Falcão AX, Gomes JF, Hoshino-Shimizu S, Suzuki, CTN. Método de preparação de amostra coproparasitológica fecal e composiçâo clarificante (Concessão de patente PTC: Prot.. 018100037856). 2010 [cited 2010 Mai 25]. Avaliable from: http://www.wipo.int/pctdb.

Faust EC, D’Antoni JS, Odom V, Miller MJ, Peres C, Sawitz W, et al. A critical study of clinical laboratory technics for the diagnosis of protozoan cysts and helminth eggs in feces. I. Preliminary communication. Am J Trop Med Hyg 1938; 18(S1): 169-183.

Fleiss JL. Statistical methods for rates and proportions. Nova York, John Wiley \& Sons; 1981.

Foreyt WJ. Diagnostic parasitology. Vet Clin North Am Small Anim Pract 1989; 19(5): 979-1000.

Garcia LS. Diagnostic Medical Parasitology. 5th ed. Washington: ASM; 2007.

Gennari SM, Kasai N, Cortez A. Ocorrência de protozoários e helmintos em amostras de fezes de cães e gatos da cidade de São Paulo. Braz J Vet Res Anim Sci 2001; 36(2): 87-91.

Gomes JF, Lumina G, Amarante AFT, Hoshino-Shimizu S, Leme DP, Dias LCS, et al. Using the TF-Test Kit for the parasitological Diagnosis in dogs (Canis familiaris). Braz J Parasitol Vet 2006; 001-043: 406.

Gomes JF, Hoshino-Shimizu S, Dias LC, Araujo AJ, Castilho VL, Neves FA. Evaluation of a novel Kit (TF-Test) for the diagnosis of intestinal parasitic infections. J Clin Lab Anal 2004; 18(2): 132-138. http://dx.doi. org/10.1002/jcla.20011

Hendrix CM, Robinson E. Diagnostic Parasitology for Veterinary Technicians. 3rd ed. Mosby; 2006.

Hoshino-Shimizu S, Gomes JF, Dias LCS. Intestinal Parasites: traditional techniques and commercial kits. Braz J Parasitol 2001; 37: 44.

Katagiri S, Oliveira-Sequeira TCG. Comparison of three concentration methods for the recovery of canine intestinal parasites from stool samples. Exp Parasitol 2010; 126(2): 214-216. http://dx.doi.org/10.1016/j. exppara.2010.04.027

Katagiri S, Oliveira-Sequeira TCG. Prevalence of Dog Intestinal Parasites and Risk Perception of Zoonotic Infection by Dog Owners in São Paulo State, Brazil. Zoonoses Public Health 2008; 55(8-10): 406-413. http:// dx.doi.org/10.1111/j.1863-2378.2008.01163.x

Kato K, Miura M. Comparative examinations. Jpn J Parasitol 1954; 3: 35.

Lumina G, Bricarello PA, Gomes JF, Amarante AFT. The evaluation of TF-Test Kit for diagnosis of gastrointestinal parasite infections in sheep. Braz J Vet Res Anim Sci 2006; 43: 496-501.
MacLure M, Willet WC. Misinterpretation and misuse of the Kappa statistic. Am J Epidemiol 1987; 126(2): 161-169. http://dx.doi. org/10.1093/aje/126.2.161

McCarthy J, Moore TA. Emerging helminth zoonoses. Int J Parasitol 2000; 30(12-13): 1351-1360. http://dx.doi.org/10.1016/ S0020-7519(00)00122-3

Martínez-Carrasco C, Berriatua E, Garijo M, Martínez J, Alonso FD, Ruiz de Ybáńez R. Epidemiological study of non-systemic parasitism in dogs in southeast mediterranean Spain assessed by coprological and post-mortem examination. Zoonoses Public Health 2007; 54(5): 195-203. http://dx.doi.org/10.1111/j.1863-2378.2007.01047.x

Meireles MV. Cryptosporidium infection in Brazil: implications for veterinary medicine and public health. Rev Bras Parasitol Vet 2010; 19(4): 197-204. http://dx.doi.org/10.1590/S198429612010000400002

Oliveira-Sequeira TCG, Amarante AFT, Ferrari TB, Nunes LC. Prevalence of intestinal parasites in dogs from São Paulo State, Brazil. Vet Parasitol 2002; 103(1-2): 19-27. http://dx.doi.org/10.1016/S03044017(01)00575-1

Rodie G, Stafford P, Holland C, Wolfe A. Contamination of dog hair with eggs of Toxocara canis. Vet Parasitol 2008; 152(1-2): 85-93. http:// dx.doi.org/10.1016/j.vetpar.2007.12.008

Sánchez-Thevenet P, Jensen O, Mellado I, Torrecillas C, Raso S, Flores $\mathrm{ME}$, et al. Presence and persistence of intestinal parasites in canine fecal material collected from the environment in the Province of Chubut, Argentine Patagonia. Vet Parasitol 2003; 117(4): 263-269. http://dx.doi. org/10.1016/j.vetpar.2003.09.014

Soriano SV, Pierangeli NB, Roccia I, Bergagna HFJ, Lazzarini LE, Celescinco A, et al. A wide diversity of zoonotic intestinal parasites infects urban and rural dogs in Neuquén, Patagonia, Argentina. Vet Parasitol 2009; 167(1): 81-85. http://dx.doi.org/10.1016/j. vetpar.2009.09.048

Sousa VR, Almeida AF, Cândido AC, Barros LA . Ovos e larvas de helmintos em caixas de areia de creches, escolas municipais e praças públicas de Cuiabá, MT. Cienc Anim Bras 2010; 11(2): 390-395. http:// dx.doi.org/10.5216/cab.v11i2.3150

Táparo CV, Perri SH, Serrano AC, Ishizaki MN, da Costa TP, Amarante AFT, et al. Comparison between coproparasitological techniques for the diagnosis of helminth eggs or protozoa oocysts in dogs. Rev Bras Parasitol Vet 2006; 15(1): 1-5.

Ueno H, Gonçalves PC. Manual for diagnosis of helminthiasis in ruminants. 4rd ed. Tokyo: J. I. C. A; 1998.

Willis HH. A simple levitation method for the detection of hookworm ova. Med J Aust 1921; 29: 375-376.

Xiao L, Cama AV, Cabrera L, Ortega Y, Pearson J, Gilman RH. Possible transmission of Cryptosporidium canis among children and a dog in a household. J Clin Microbiol 2007; 45(6): 2014-2016. http://dx.doi. org/10.1128/JCM.00503-07 